Bangl. J. Vet. Med. (2009). 7(2) : $326-331$

\title{
PREVALENCE OF INFECTIOUS DISEASES OF BROILER CHICKENS IN GAZIPUR DISTRICT
}

\author{
M. S. Ahmed*1 ${ }^{1}$ A. Sarker ${ }^{1}$ and M. M. Rahman ${ }^{2}$ \\ ${ }^{1}$ Department of Medicine and Surgery, Faculty of Animal Science and Veterinary Medicine, \\ Patuakhali Science and Technology University, Babugonj, Barisal-8210, Bangladesh, \\ ${ }^{2}$ Laboratory Medicine, Islami Bank Hospital, Motijhil, Dhaka, Bangladesh
}

\begin{abstract}
The study was conducted to determine the occurrence of infectious diseases in broiler chickens at kapasia in Gazipur district during the period from $16^{\text {th }}$ October to $16^{\text {th }}$ December 2008. Detection was made on the basis of history, clinical findings and post-mortem lesions. A total of 199 broiler chickens were examined during the study where Colibacillosis 104 (52.26\%), Mycoplasmosis 25 (12.56\%), Salmonellosis 02 (1.01\%), Omphalitis 23 (11.56\%), Coccidiosis 09 (4.52\%), Gumboro 22 (11.06\%), Mycotoxicosis 11 (5.53\%) and mixed infection of Gumboro \& Coccidiosis 03 (1.51\%) were recorded. In the conclusion it has been remarked that Collibacillosis is a major problem for broiler production and hence poultry farmers can not earn their profit perfectly due to adverse effect of those diseases. Further laboratory examination is needed to confirm the identified diseases.
\end{abstract}

Key words: Clinical findings, necropsy findings, broiler chickens

\section{INTRODUCTION}

Poultry industry is an emerging agribusiness starting practically during eighties in Bangladesh. But mortality of chickens due to various infectious and non-infectious diseases is a major constrains for profitable poultry production. Farmers face a wide range of poultry diseases, which reduce the optimal production of flock. Ali (1994) reported about 30\% mortality of chickens in Bangladesh every year due to outbreaks of several diseases. Diseases in broiler significantly affect the productivity and health status (Chanie et al., 2009). Rahman et al., (2007) reported Salmonellosis 50.90\%, Omphalitis 28.42\%, Colibacillosis 13.36\%, Mycoplasmosis 2.55\%, Necrotic enteritis $1.88 \%$ and Infectious coryza $0.56 \%$ in chickens. Infectious bursal disease is an important viral disease which causing 10-40\% mortality in broiler flock (Sah et al., 1995). Coccidiosis is one of the most important diseases of poultry, it results in a great economic loss all over the world (Braunius, 1980). Nematollahi et al. (2009) reported overall prevalence of coccidiosis in broiler chickens 55.96\%. Most of these disease cripples the immune system of the affected birds that in turns result vaccination failure and make them highly susceptible to other infectious diseases. As such poultry industry of this country will be logging behind unless the cases of such diseases mortality are known and requisite control measures of different fatal diseases are efficiently achieved. Considering the above facts the present study was undertaken to study the occurrence of the infections diseases in broiler chicken.

\section{MATERIALS AND METHODS}

The study was conducted at UVH (Upazila Veterinary Hospital), Kapasia, Gazipur during the period from $16^{\text {th }}$ October 2008 to $16^{\text {th }}$ December 2008. A total 199 sick and dead broiler chickens were examined during the study. The clinical findings and the farmer's complaints were also considered.

\section{Diagnosis of diseases}

The bird was examined systematically and recorded the postmortem changes during necropsy (Charlton, 2000).

\section{Colibacillosis}

The clinical signs showed that sick birds were dullness, depression, reduced intake of food and water, huddling at the corner of the shed, loss of body weight, brown color droppings etc. Post-mortem examination revealed pericarditis, petechial haemorrhages and formation of the fibrinous layer on the heart, air sac infection, enteritis, dilation of the last part of the intestine. These lesions are similar to Gross (1988) and North and Bell (1990) pathological investigation.

\footnotetext{
*Corresponding author: e-mail: vetselim476@yahoo.com.
} 


\section{S. Ahmed and others}

\section{Salmonellosis}

The affected birds exhibited somnolence, ruffled feather, whitish to greenish diarrhoea, chalky white excreta adhered with the vent \& anemic comb and wattle. Postmortem examination revealed enlarged and necrotic foci on liver, greenish to bronze color liver.

\section{Infectious bursal disease}

The recorded clinical signs were soiled vent, feathers, whitish or watery diarrhea, anorexia, trembling, severe prostration and death. Post-mortem lesion includes pint point haemorrhage in the thigh and breast muscles, enlarged and necrosed bursa of fabricius, yellowish gelatinous membrane found over the swollen bursa, hemorrhage on the bursa. Mucous containing drooping found in the ascending part of small intestine.

\section{Mycoplasmosis}

The clinical findings showed that oculo-nasal discharge, gasping on mouth, lower feed consumption etc. Postmortem examination showed that catarrhal exudates in nasal and para nasal passages, trachea, bronchi, cloudy air sacs and congestion of the lungs.

\section{Omphalitis}

Birds were found dead without showing any clinical signs \& some were lethargic and depressed with poor growth performance. The necropsy examination revealed that considerable thickened unabsorbed yolk in all dead chicks, abdominal contents cloudy and malodorous, yolk appeared highly inflammed, thickened and edematous. The blood vessels around the yolk were highly congested. These observations are similar to Harry (1957) and Kamal (1989).

\section{Coccidiosis}

Clinical findings of coccidiosis were ruffled feather, drowsiness, bloody diarrhea, anemia \& high mortality. Post mortem examination showed that hemorrhage on caecal tonsil, loss of tonacity of two caeca, clotted blood engorsed in the cecum, white foci present in the mucous membrane of intestine, catarrhal enteritis. These lesions are more similar to Rahman (1992) investigation.

\section{Mycotoxicosis}

The post-mortem lesions of the dead chickens showed blackish or yellowish discoloration of liver, friable(fragile liver), hepatomegaly. The gallbladder is enlarged and filled with bile. In case of mild infection blackish discoloration of the intestine was observed. These observations support to the report Ortatatli and Oquez (2001).

\section{RESULTS AND DISCUSSION}

Analysis of the data revealed that 199 broiler chickens were examined during the study where Colibacillosis 104 (52.26\%), Mycoplasmosis 25 (12.56\%), Salmonellosis 02 (1.01\%), Omphalitis 23 (11.56\%), Coccidiosis 09 (4.52\%), Gumboro 22 (11.06\%), Mycotoxicosis 11 (5.53\%) and Gumboro and Coccidiosis 03 (1.51\%) were recorded.

\section{Colibacillosis}

Colibacillosis was recorded 52.26\%. Khan et al. (1998) reported 12\% which is lower than the performed study. Among the infectious diseases colibacillosis was found highest prevalence. Pandey et al. (1998) conducted a systemic study on Escherichia coli outbreak prevalence in which November to March recorded much higher number of outbreaks due to hot, humid and rainy season, which support the present study.

\section{Salmonellosis}

Salmonellosis was recorded $1.01 \%$ in broiler birds with necrotic foci on liver. Chisti et al. (1985) reported that bronge discoloration of liver $75 \%$, \& necrotic foci on liver $11 \%$, which support the present necropsy findings. The prevalence of salmonella infection was higher in summer season than in winter (Sarker, 2004). It might be due to the influence of hot weather and sudden rainfall. The present study was done in winter month and supported by Sarker (2004).

\section{Infectious bursal disease}

Infections bursal disease was recorded in $11.06 \%$ broiler birds. Pathological investigation and prevalence of the disease are similar to Saha and Majumder (1997) and Sil et al. (2002). Prevalence of Gumboro disease also reported by Anjum (1990) and Kim et al. (1996) as 3.1\% and 27.3\%, respectively. 
Infectious diseases in broiler chickens

Table1. Prevalence of infectious diseases in broiler chickens

\begin{tabular}{|l|l|l|l|}
\hline Sl. No. & Disease & No. of broiler chickens & Percentage (\%) \\
\hline 01 & Colibacillosis & 104 & 52.26 \\
\hline 02 & Mycoplasmosis & 25 & 12.56 \\
\hline 03 & Salmonellosis & 02 & 1.01 \\
\hline 04 & Omphalitis & 23 & 11.56 \\
\hline 05 & Coccidiosis & 09 & 4.52 \\
\hline 06 & Gumboro & 22 & 11.06 \\
\hline 07 & Mycotoxicosis & 11 & 5.53 \\
\hline 08 & Gumboro and Coccidiosis & 03 & 1.51 \\
\hline
\end{tabular}

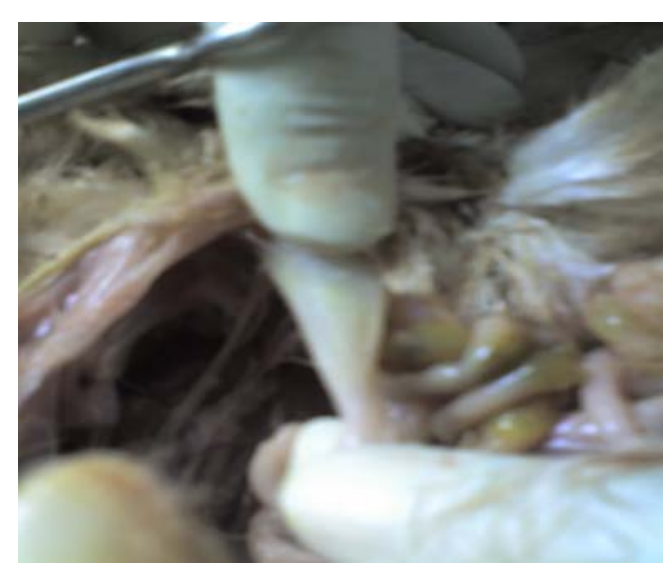

Fig. 1. A typical lesion of acute Colibacillosis containing dilatation of the colon.

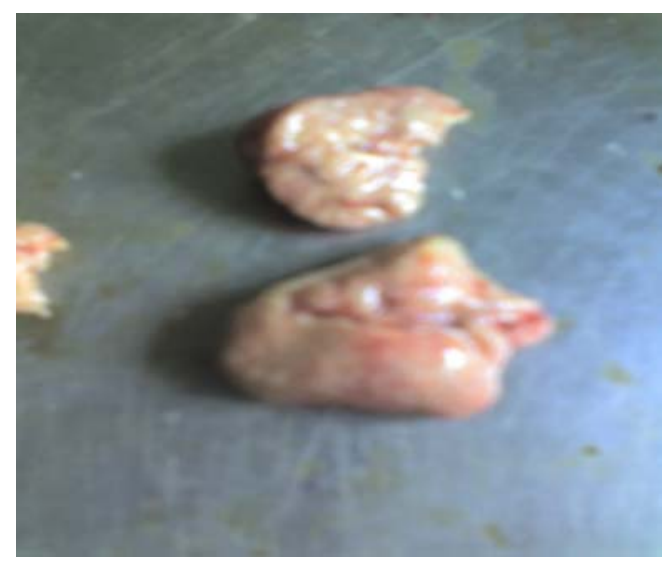

Fig. 3. A typical lesion of Gumboro disease (pin point hemorrhage found in the mucous membrane of swollen bursa).

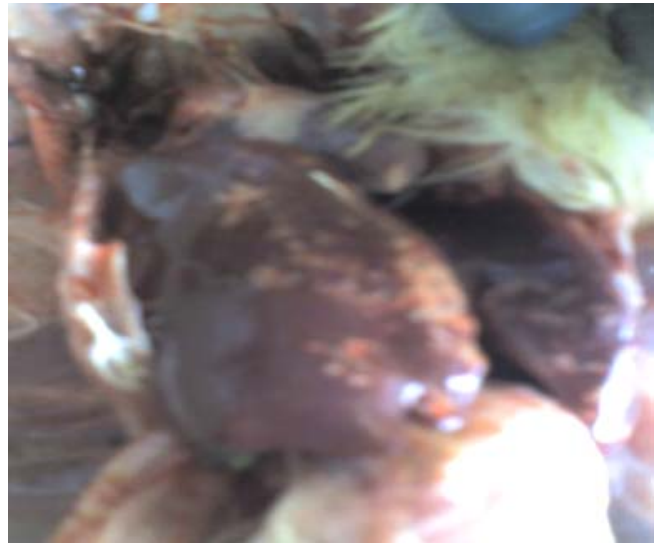

Fig. 2. A typical lesion of Salmonellosis (focal necrosis and glistening of surface of the liver).

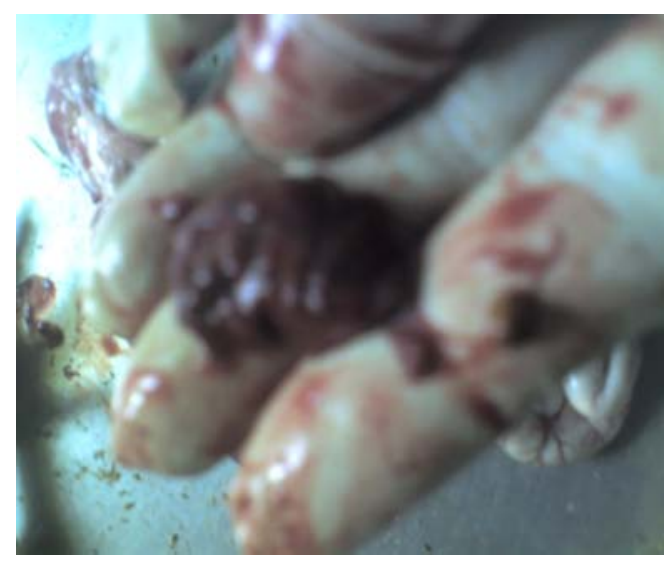

Fig. 4. A typical lesion of Mycoplasmosis (congested lung). 


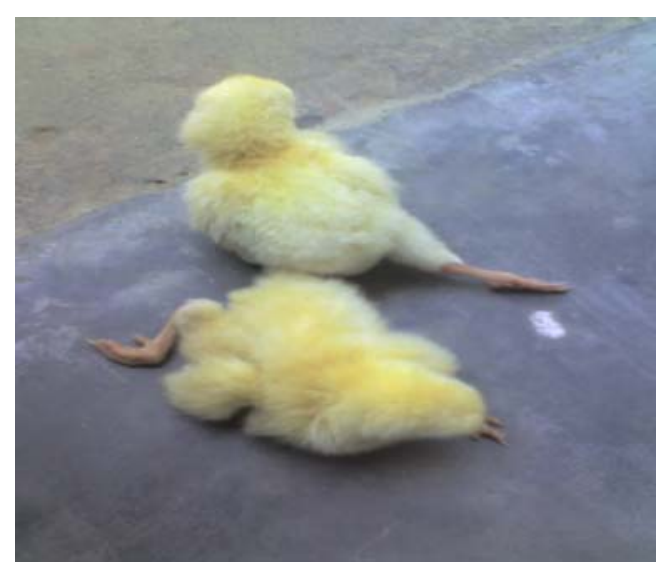

Fig. 5. A typical gross finding of Omphalitis due to colibacillosis.

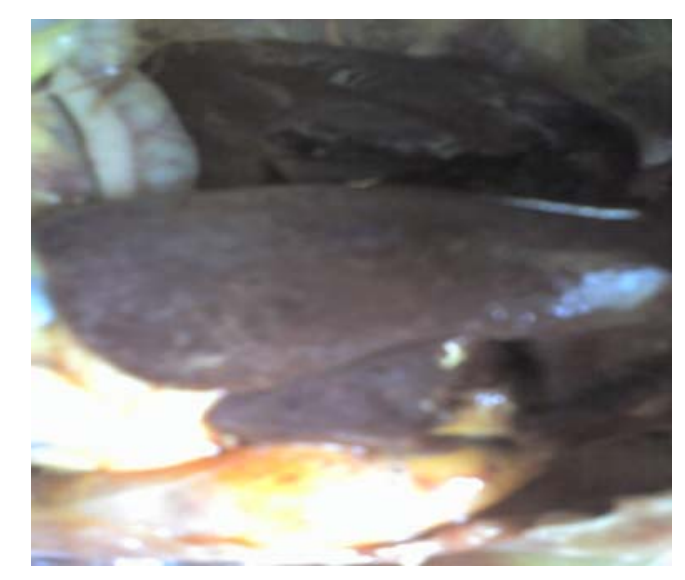

Fig. 7. A typical lesion of acute Mycotoxicosis (blackish discoloration and fragile liver).

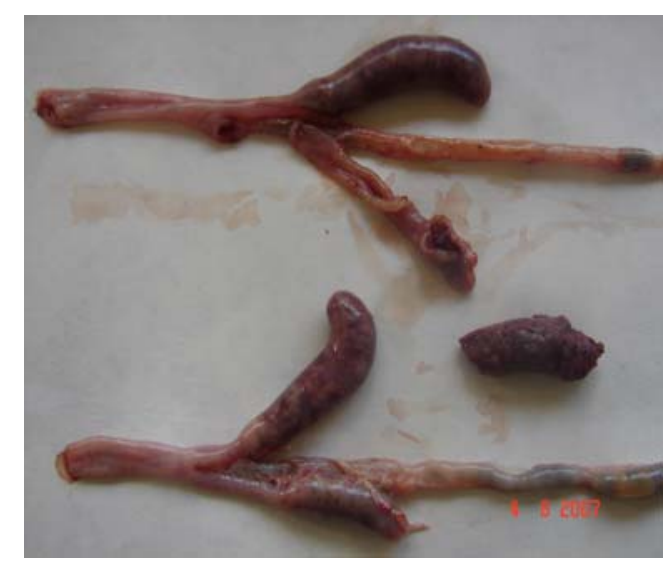

Fig. 6. A typical lesion of Coccidiosis (Cecum engorged with clotted blood).

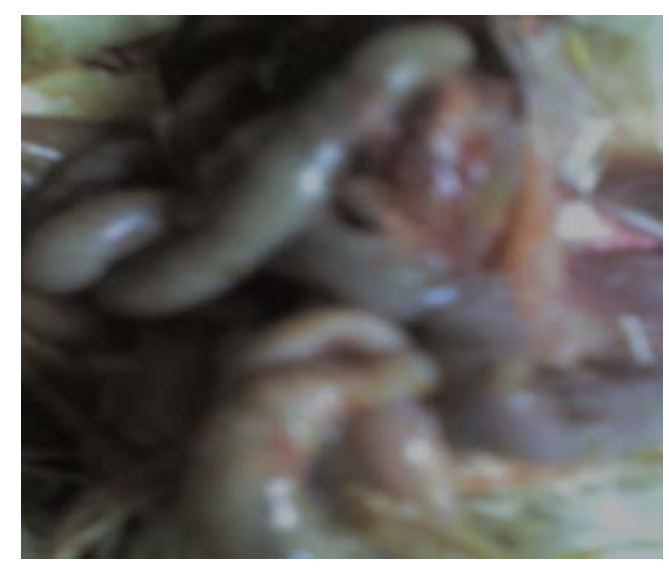

Fig. 8. A typical lesion of mild Mycotoxicosis (blackish discoloration of the intestine)

\section{Mycoplasmosis}

Mycoplamosis was recorded $12.56 \%$ in broiler birds. Anjum (1990) reported 5.8\% which is lower than recorded study. Clinical and pathological lesions are supported by Bajwa et al. (1992). The factors which contribute the mycoplasma infection are poor ventilation, moist litter and no restriction on movement of technical personnel visitors and such other persons as well as biosecurity measures (Dulali, 2003).

\section{Omphalitis}

Omphalitis was recorded $11.56 \%$. Bhattacharjee et al. (1996) revealed incidence of Omphalitis $8.9 \%$ in chicks which is lower than the present study. Infection might be due to fecal contamination of eggs, which is a most important source of yolk sac infection an other sources might be ovarian infection or salpingitis.

\section{Coccidiosis}

Coccidiosis was recorded $4.52 \%$ in broiler chickens which is lower than the Saleque et al. (2003) who reported $7.2 \%$ in layer birds. Some factors like wet litter improper cleaning of poultry houses and disinfection before introducing day old chicks increase the susceptibility of coccidiosis in poultry farm (Sharif, 2002). 


\section{Mycotoxicosis}

Mycotoxicosis was recorded 5.53\%, which is higher than Yunus et al. (2009) who reported incidence of Mycotoxicosis in poultry 3.9\%. The disease might be due to poor management of litter, increase moisture content in feed and lack of biosecurity measures.

\section{Gumboro and Coccidiosis mixed infection}

The present study revealed that $1.51 \%$ broiler chickens affected with Gumboro and Coccidiosis mixed infection.

\section{REFERENCES}

1. Ali MJ (1994). Current status of veterinary biologics production in Bangladesh and their quality control. Proceedings of the BSVER symposium held on July 28, 1994 at NIPSOM auditorium, Mohakhali, Dhaka, Bangladesh.

2. Anjum AD (1990). Prevalence of poultry diseases in and around Faisalabad and their relationship to weather. Pakistan Veterinary Journal 10: 42-45.

3. Bajwa NZ, Siddique M and Javed MT (1992). Pathogenesis of Escherichia coli in previously Mycoplasma gallisepticum infected layers chicks. Journal of Islamic Academy of Sciences 5(2): 123-126.

4. Bhattacharjee PS, Kundu RL, Biswas RK, Majumder JU, Hossain E and Miah AH (1996). A retrospective analysis of chicken diseases diagnosed at the Central Disease Investigation Laboratory, Dhaka. Bangladesh Veterinary Journal 30 (3-4): 105-113.

5. Braunius WW (1980). Monitoring the biological performance in broilers with special regard to subclinical coccidiosis. Archiv fur Geflugelkunde 44: 183-187.

6. Chanie M, Neqash T and Tilahan SB (2009). Occurrence of concurrent infectious diseases in broiler chickens is a threat to commercial poultry farms in Central Ethiopia Tropical Animal Health and Production 41 (7): 1309-17.

7. Charlton BR (2000). Bacterial Diseases. In: Avian Disease Manual. 5th edn. The American Association of Avian Pathologists, USA.

8. Chishti MA, Khan MZ and Irfan M (1985). Pathology of liver and spleen in avian salmonellosis. Pakistan Veterinary Journal 5 (4): 157-160.

9. Dulali RS (2003). Seroprevalence and pathology of Mycoplasmosis in Sonali chickens. MS thesis, submitted to the Department of Pathology, Faculty of Veterinary Science, Bangladesh Agricultural University, Mymenisngh.

10. Gross WB (1988). Colibacillosis. In: Disease of Poultry. Hofstad MS (ed). $8^{\text {th }}$ edn., Iowa State University Press, Iowa, USA. pp. 273-275.

11. Harry EG (1957). The effect on embryonic and chick mortality of yolk contamination with bacteria from the hen. Veterinary Record 69: 1433-1440.

12. Kamal AHM (1989). Pathological investigation on the mortality of chicken in Bangladesh Agricultural University poultry farm. MSc thesis, Department of Pathology, Faculty of veterinary Science. BAU, Mymensingh.

13. Khan M, Bari ASM, Islam MR, Das P M and Ali MY (1998). Pullorum disease in semi mature chicks and its experimental pathology. Bangladesh Veterinary Journal 32: 124-128.

14. Kim HJ, Kong MI, Chung UK, Kang MI and Chung UI (1996). Survey of enteric diseases in chickens. Korean Journal of Veterinary Research 36: 1007-1012.

15. Nematollahi A, Moghaddam G and Pourabad RF (2009). Prevalence of Eimeria species among broiler chicks in Tabriz (Northwest of Iran). Mun. Ent. Zool. 4(1):53-58.

16. North MO and Bell DO (1990). Commercial Chicken Production Manual. $4^{\text {th }}$ edn., Chaman and Hall , International Thomson Publishing, New York, USA.

17. Ortatatli M and Oquez H (2001). Ameliarative effects of dietary clinoptilolite on pathological changes in broiler chicken during aflatoxicosis. Resvet Sci. 71(1): 59-66.

18. Pandey GS, Tuchili CM, Kaneuchi C, Waya W and Nyeleti G (1998). Study on avian colibacillosis outbreak and drug sensitivity of Escherichia coli isolates in Luraka. Indian Veterinary Journal 75: 754-755.

19. Rahman M (1992). Comparative efficacy of common sulfur drugs against Coccidiosis in poultry. MS Thesis. Dept. of Pharmacology. Bangladesh Agricultural University, Mymensingh-2202, Bangladesh.

20. Rahman MM, Rahman AZ and Islam MS (2007). Bacterial diseases of poultry prevailing in Bangladesh. Journal of Poultry Science 1(1): 1-6.

21. Sah RL, Kataria JM, Arya SC and Verma KC (1995). Outbreaks of acute infectious bursal disease causing high mortality in chicken. Indian Journal of Comparative Microbiology, Immunology and Infectious Diseases 16 (1 \&2): 7-13.

22. Saha Ak and Majumder AK (1997). Report of infectious bursal disease among grower chickens in Tripura. Indian Veterinary Journal 74: 515-516.

23. Saleque MA, Rahman MH and Hossain MI (2003). A retrospective analysis of chicken diseases diagnosed at the BRAC poultry diagnostic centre of Gazipur. Bangladesh Journal of Veterinary Medicine 1 (1). 29-31.

24. Sarker SK (2004). Epidemiological study of Salmonella and Mycoplasma infection in selected model breeder poultry farms of Bangladesh. MS thesis, submitted to the Department of Microbiology and Hygiene, Faculty of Veterinary Science, Bangladesh Agricultural University, Mymensingh, Bangladesh. 


\section{S. Ahmed and others}

25. Sharif M (2002). Current status of chicken coccidiosis in Gazipur and coccidiosis control in semi scavenging layer pullets. MS Thesis, submitted the Department of Parasitology, Faculty of Veterinary Science, Bangladesh Agricultural University, Mymensingh, Bangladesh.

26. Sil Gc, Das PM, Islam MR and Rahman MM (2002). Management and diseases problems of cockerels in some farms of Mymensingh, Bangladesh. International Journal of Poultry Science 1: 102-105.

27. Yunus AW, Nasir MK, Aziz T and Bohm J (2009). Prevalence of poultry diseases in district Chakwal and their interaction with Mycotoxicosis: effects of season and feed. The Journal of Animal and Plant Sciences 19 (1): 1-5. 